\title{
Translator's Subjectivity in Parody Translation from the Perspective of Skopostheorie
}

\author{
Wang Fang \\ School of Foreign languages, Hubei University of Technology, Wuhan, 430068, China
}

\begin{abstract}
This paper is intended to interpret the translators' subjectivity in parody translation from the perspective of Skopostheorie. According to Skopostheorie, translation is a purposeful activity based on the source text. Under the guidance of Skopostheorie, the translators display their subjectivity in accepting the original text and recreating the target text according to their purpose, and the translators' subjectivity displays more obviously and thoroughly in parody translation.
\end{abstract}

Index terms - Skopostheorie, translators' subjectivity, parody translation

\section{Introduction}

The role of translator has been an important topic for discussion in many schools' translation theories. But it has never been emphasized as it has by functionalists: The translator is the expert in translational action. He/she is responsible for the performance of the commissioned task, for the final translatum (i.e. the translated text). As far as parody is concerned, it is not only a linguistic concept, but also takes on culture-specific features. To make sure of the success of crosscultural communication and fulfill the purpose of the text, translators should display their subjectivity and creativity fully to guarantee the successful parody translation.

\section{Basic Concepts of Skopostheorie}

Skopos theory is an approach to translation, which was developed in Germany in the late 1970s. It reflects a general shift from predominantly linguistic and rather formal translation theories to a more functional and socio-culturally oriented concept of translation. This shift drew inspiration from communication theory, action theory, text linguistics and text theory as well as from movements in literary studies towards reception theories. Apart from Hans J. Vermeer, who first put forward Skopostheorie, Justa. Holz-Mänttäri and Christiane, Nord further developed the theory. Skopos theory claims that translation is not a process of transcoding but a specific kind of human action, and every action has its own purpose(skopos), so the translation purpose determines the translation means. Therefore, knowing the function and the purpose of the original text is very important to translators. In Vermeer's words, translating is "an intentional, interpersonal, partly intercultural interaction based on a source text." (Nord, 2001: 18). By putting forward the concept that translation is a purposeful activity, Skopostheorie endows much more freedom to the translator in his/her choice of the appropriate strategies to fulfill the intended purpose, the translator thus plays a more active and creative role in the process of translation. What the translator needs to do is to try every means to meet the "end". There are three basic rules in Skopostheorie to ensure the quality of translation. They are Skopos rule, Coherence (intratextual coherence) rule and Fidelity (intertextual coherence) rule. Skopos rule is the top ranking rule for any translation. Any translational action is determined by its Skopos and 'the end justifies the means' (Nord, 200: 29). Of these three rules, Skopos rule is the predominating one. Intertextual coherence (fidelity rule) is considered to subordinate to intratextual coherence (coherence rule) and both are subordinate to Skopos rule. In the case of parody, frequently adopted in advertisements, news reports and many other text varieties, the translator should never neglect the historical and cultural context, but should make efforts to shorten and diminish the gap and obstacle in the cross-cultural communication. Otherwise, the translation may fail to fulfill the purpose of the text. Generally speaking, parody translation concerned with the culture factors could be subdivided into two cases. First, for the parody contained in the source text, which has the same image or association and function in both source and target language, the translator could reserve the original image or association during the translational process. Second, for the parody, which has different or unfamiliar image or association in target language, the translator could only converse the original image or association and adapt his text to the norms and conventions of the target culture and language.

\section{Translators' Subjectivity in parody translation from the perspective of Skopostheorie}

\subsection{Subject of Translation and Subjectivity of the Translator}

Translation is not merely the production of a text equivalent to another text, but rather a complex process of rewriting the original, which runs parallel both to the overall view of the language, and to the influences and the balance of power that exists between one culture and another. Eugene A. Nida points out that "the role of language within a culture and the influence of the culture on the meanings of words and idioms are so pervasive that scarcely any text can be adequately understood without careful consideration of its cultural background." (Nida, 1993:i). According to Skopostheorie, translation is a human action designed to achieve a special purpose. Thus the translator as the agent of translating, is surely the subject with the special purpose and this special identity indicates that translator's subjective initiative is of necessity in the translating activity.

As we all know, many elements such as the writing style of the author, the background and culture against which the 
work is produced, and the aesthetic beauty encoded in the original text pose challenges to the translator. Hence the translator can hardly avoid being influenced by these factors while exerting his or her subjectivity. However, Subjectivity is the distinctive inner character of every human being. The translator's linguistic competence and cultural background will inevitably affect the translating process unconsciously. Skopos theory claims that the translator surely have the specific purpose in his/her mind before taking an action of translating. Bearing the purpose in mind, the translator decides to choose what kind of translating material to translate. Vermeer holds that any text is just an "offer of information" (Reiss and Vermeer 1984:72ff) from which individual receiver selects the items appealing to him/her. So it is the Skopos that determines what to translate and how to translate. It means that the source text should no longer be seen as the "sacred original", and the purpose of the translation can no longer be deduced from the source text but depends on the expectations and needs of the target readers. For example, in advertising, an advertiser sometimes depends on translator's professional opinion on the target culture to design or revise the advertisement. Thus, this gives the translators much freedom and makes their subjectivity display more thoroughly in choosing and interpreting the source text. Furthermore, Skopostheorie holds that "the end justifies the means"(.Nord, 2001:29), that is, the translation purposes determine the translation methods and strategies. During the process of translating the display of the translator's subjectivity also exists in the choice of translation methods and strategies, which are also determined by his/her translation purpose. In translating the same text different translators may adopt different translation strategies for different purposes. One typical example is the translation of 《红楼梦》. One version is A Dream of Red Mansions, translated by Yang Xian yi and his wife Gladys Yang, and the other is The Story of the Stone, translated by David Hawkes and his son-in-law. Generally speaking, the former is considered to be foreignized for Yangs' purpose is to faithfully convey the value and soul of Chinese culture and convey the life of Chinese People with their happiness and grief, while the later is domesticated for Hawkes attempts to modestly convey to the reader some of the pleasure this Chinese novel has given him. Anyway, both translated versions are considered as very influential and well received by their target readers, for in accordance with Skopostheorie, as long as the translation purpose is fulfilled it is a good translation.

Therefore, translator's subjectivity can be defined as follows: on the basis of respecting the translation object, the translator, as the subject of translation, exhibits his/her initiative and skills in the process of achieving the translation purpose. Translator's subjectivity is not only reflected in the artistic recreation at the level of comprehension, interpretation and language conversion, but also in the selection of the text to be translated, the translation method, the translation purpose and the expected cultural effects of the translation.

\subsection{Translator's Subjectivity in Choosing the Appropriate Parody Translation Strategy}

Parody, as a rhetorical device, is a very efficient and important linguistic means to assist the text of different varieties to achieve specific communicative purposes, say, to promote the sale of a product, to inform the readers of the news value or to transmit the artistic and linguistic beauty of the literature work. Parody, on the one hand, is a concept based on the linguistic level. On the other hand, to some extent, it is also a category based on the culture level. The cultural-oriented functional approach to translation studies, the Skopostheorie in particular, is highly relevant to parody translation which involves cross-cultural communicative action. In Skopostheorie, the target text receiver is assigned a higher status and a more influential role. During the practice of parody translation, the translator should take into full consideration the information about the target audience. Their world knowledge, traditional customs and social values they cling to are to be carefully observed and analyzed. All the assumptions about the target audience are different from those made by the original author, because source-text receivers and target-text receivers belong to different cultures and language communities. This means the translator cannot and needn't offer the same amount and kind of information as the sourcetext producer. What the translator does is to offer another kind of information in another form. Having known clearly the translation brief, the translator then has much freedom to choose various strategies to achieve the specific communicative functions so as to fulfill the brief. Equivalent effect is not always the primary concern of translating parody, and at times cultural transposition or adaptation is inevitable in this type of translating due to their prominent cultural characteristics. In many cases, to gain parody's aesthetic value,. Creativity in parody translation is the embodiment of the translator's subjectivity to certain extent. The following examples can illustrate how the translator adopt appropriate translation strategies and display his/her subjectivity in parody translation.

Example 1: 黛玉不觉笑了: “那里来的渔翁!”......黛玉笑 道: “我不要他。戴上那个, 成个画儿上画的 和戏上扮的渔婆了。”及说了出来, 方想起话 未忖度, 与方才说宝玉的话相连, 后悔不及, 羞得脸飞红, 便伏在桌上嗽个不住。( 曹雪芹: 《红楼梦》)

Version A: "Where does this fisherman come from?" she greeted him laughing... "No, thank you." Tai-yu chuckled. "If I wore one of those I should look like the fisherman's wife in paintings and operas." (Translated by Yang Hsien-yi \& Gladys Yang)

Version B: Dai-yu laughed at the spectacle he presented. "The Old Fisherman! Where have you just sprung from?"...'I don't want one, thank you," said Dai- yu laughing. "If I were to 
wear one of those. I should look like one of those old fisherwomen you see in plays and paintings." (Translated by David Hawkes)

In comparison of the two translated versions, the former is literal translation and seems much more reserved, while the latter appears more creative by imitating and achieves more humorous effect on target readers. Obviously, the translator of Version B adopted a more flexible strategy. The created word "fisherwoman" by parody endows the TT the same communicative function as that of the ST which implies that Dai-yu thrusted in the utterance without hesitation.

Example 2: 乐百氏矿泉水, “净”在不言中。

Robust mineral water, as clear as crystal.

This ad slogan “净在不言中” is a phonetic parody of “尽 在不言中”.The quality of the mineral water with the brand of “乐百氏” cannot be better valued with only one substitution of “净” for “尽”. Considering the similar parodic phrase with equivalent meaning is not available in the target text, with the repetition of the initial consonant $/ \mathrm{k}$ / in 'clear' and 'crystal' alliteration is employed here to replace the original figure of speech. By highlighting the sounds of the two words, this ad catches the attention of the audience and makes the idea impressed on the audience and thus easier for them to remember. Undoubtedly, this translation, on the one hand has achieved the informative and vocative function of advertising, on the other hand, has reproduced its original rhetorical effect.

\section{Example 3: 五儿急的便说: “原是宝二爷屋里的芳官给我 的。”林之孝家的说：“不管你“方官”圆官”! 现有了赃证！我只呈报了, 凭你主子前辩 去! ”( 曹雪芹:《红楼梦》)}

In desperation then $\mathrm{Wu}$-erh confused, "That was given me by Fang-kuan in Master Pao's place." "I don't care who gave it you," snapped Mrs.Lin. "Now that we have evidence of the theft, I shall report it and you can explain it to the mistresses." (Translated by Yang Hsien-yi \& Gladys Yang)

In this example, it is not difficult to identify the parodic and the original for both of them appear in the same dialogue. First, the word “方官” has a homophonic morpheme with “芳 官”, then the prodic word “圆官” is created with the opposite morpheme to “方官”. By parody, the writer vividly depicts Mrs Lin`s humorous and oratorical character. In order to smoothly and plainfully transfer what the speaker implies to the target reader, it is paraphrased as "I don't care who gave it you".

Example 4: 在家靠自己, 出门靠国旅。(an ad for a travel agency)

At home you are your own boss; in China your Aladdin's lamp is at CITS
This advertisement for a travel agency parodies the famous saying “在家靠自己, 出门靠朋友” to convince the overseas travellers that “国旅” is reliable. We know that the function and purpose of advertising are selling the products or offering services for the consumers. In order to achieve this goal, translation needs to be accepted by the target text readership. If we translate it literally into 'international travel agency', it is difficult for the target reader to have the same association as the original. Hence, the translator creatively turns to the well-known image 'Aladdin's lamp' in English and render the translation into "At home you are your own boss; in China your Aladdin's lamp is at CITS". Therefore, CITS's quick and convenient services are vividly manifested with strong persuasive force and thus it is more acceptable to the English audience. Undoubtedly, the intended function of advertising in the target text is also achieved.

To sum up, in the above parody translations the translators use their subjectivity and choose appropriate and effective translation strategies, such as imitating, substituting, paraphrasing and adapting, to achieve the ultimate purpose of parody translation successfully.

\section{Conclusions}

This paper probes into the translators' subjectivity in parody translation from the perspective of Skopostheorie. According to Skopostheorie, the essence of translation is purposeful, communicative, and cross-cultural. Plus, the translator's social status has been upgraded from a slavish imitator to a more creative decision maker. The translator is entitled to more freedom to choose what he/she thinks appropriate to do the translation in the light of Skopostheorie, However, translator's subjectivity cannot be exaggerated. The translator mustn't casually alter the information of the original or coin something from nothing. That is to say, the translator should exert his or her subjectivity to an appropriate degree to ensure successful translation. So some restrictions should be imposed on the exertion of translator's subjectivity, and the basic one is that creative translation should be done on the basis of the source text.

\section{References}

[1] Hawkes, David. The story of the Stone. Harmondsworth: Penguin Books Ltd,.

[2] Nida, Eugene A. Language, Culture and Translating. Shanghai: Shanghai Foreign Languages Education Press, 1993.

[3] Nord, Christiane. Translation as a Purposeful Activity: Functionalist Approaches Explained. Shanghai: Shanghai Foreign Language Education Press, 2001.

[4] Vermeer, Hans. A Framework for a General Theory of Translating. Heidelberg: Heidelberg University, 1978

[5] Yang Hsien-yi \& Gladys Yang, A Dream of Red Mansions. Beijing: Foreign Languages Press, 1978.

[6] Li Dingkun. Chinese and English Figures of Speech-Comparison and Translation. Wuhan: Central China Normal University Press, 1994

[7] Xu Jun. Creative Treason and the Establishment of Translational Subjectivity. Chinese Translators Journal, 2003 (1):6-11 